\title{
Acoustic Trap for Female Mediterranean Fruit Flies
}

\author{
A. Mizrach, A. Hetzroni, M. Mazor, R. W. Mankin, T. Ignat, \\ J. Grinshpun, N. D. Epsky, D. Shuman, R. R. Heath
}

\begin{abstract}
Medflies (Ceratitis capitata) are among the world's most economically harmful pests. In addition, the costs of worldwide monitoring and control are expensive, exceeding $\$ 800$ million per year in Israel and the U.S. alone. Efficient traps are vitally important tools for medfly quarantine and pest management activities. They are needed for control as well as early detection, for predicting dispersal patterns, and to estimate medfly abundance within infested regions. Efficient tools to attract and catch the primary target, namely reproductively viable females, are a particularly important need. The present research aimed to evaluate the attractiveness of male calling song and synthetic sounds to mate-seeking female medflies, as a contribution to the design and testing of a trap (patent pending) based on acoustic lures. In order to evaluate the adequacy of the experimental setup, the courtship behavior of female medflies in the presence and absence of calling male flies was observed. Male medfly calling song and synthetic tones were played at various intensities to laboratory-reared and wild female medflies during the morning and early afternoon periods of peak sexual activity. For most treatments, it was found that the laboratory and wild female flies were attracted to sites near broadcasting speakers more than to sites without sound. The strongest effect was with traps broadcasting $150 \mathrm{~Hz}$ signals at $67 \mathrm{~dB}$ sound pressure level, which attracted $28 \%$ more females than non-sound-baited traps. This study indicates that there is a possibility of using sound to enhance the attractiveness of traps to mate-seeking female medflies.
\end{abstract}

Keywords. Acoustic communication, Behavior, Ceratitis capitata, Digital signal processing, Entomology, Insect pest detection, Mediterranean fruit fly.

$\mathrm{F}$ ruit flies are important agricultural pests in most parts of the world. The Mediterranean fruit fly Ceratitis capitata (medfly) is polyphagous, attacking some 250 different types of fruit, including citrus as well as many deciduous and subtropical fruits (Fimiani, 1989). The most common and effective systems currently used to control the medfly are ultra-low-volume aerial spraying of poison-bait mixture (Rossler, 1989) and cover sprays. Increasing public awareness of the environmental dangers from pesticides has generated interest in the development of more environment-friendly alternatives. One method to reduce these environmental dangers is to employ integrated pest management techniques. A critical component in many integrated pest management programs is the use of pest monitoring tools to identify and treat new infestations before they spread to large areas.

Attractants, especially for females, are of major interest as monitoring tools and controls. In general, two types of

Article was submitted for review in November 2003; approved for publication by the Biological Engineering Division of ASABE in July 2005. Presented at the 2003 ASAE Annual Meeting as Paper No. 037067.

The authors are Amos Mizrach, ASABE Member, Senior Principal Scientist, Amots Hetzroni, Scientist, Michal Mazor, Research Engineer, Timea Ignat, Engineer, and Joseph Grinshpun, Research Engineer, Agricultural Research Organization, The Volcani Center, Bet Dagan, Israel Richard W. Mankin, Research Entomologist, and Dennis Shuman, Research Engineer, USDA-ARS Center for Medical, Agricultural, and Veterinary Entomology, Gainesville, Florida; and Nancy D. Epsky, Research Entomologist, and Robert R. Heath, Research Chemist, USDA-ARS Subtropical Horticulture Research Station, Miami, Florida. Corresponding author: Amos Mizrach, Agricultural Research Organization, The Volcani Center, P.O. Box 6, Bet Dagan 50250, Israel; phone: +972-3-9683451; fax:+972-3-9604704; e-mail:amos@volcani.agri.gov.il. attractants are in use for medfly monitoring and control. Trimedlure is a powerful attractant for males but not females, and is used mainly in monitoring (Rossler and Chen, 1994). Food lures, mostly protein hydrolysates, that are particularly attractive to protein-deficient females are used as baits in poisoned-bait sprays. Ammonia released from such bait is the key component to attract the females (Mazor et al., 1987). Other female attractants based on emulated pheromones (Heath et al., 1991) and plant odors (Jang and Light, 1996) have been tested with limited success.

Part of the research on development of new fruit fly detection and control techniques has been focused on mating behavior (Heath et al., 1991). Typically, traps based on sexual communication signals are highly selective and therefore more efficient. However, the medfly has a rich and varied courtship, which complicates efforts to develop communication-based trapping systems. Medfly males produce songs as part of their sexual communication system. Sivinski et al. (1989) identified three distinct sounds in medfly males' acoustical signals: (1) the calling song, produced simultaneously with pheromone emission and often in the absence of other nearby flies; (2) the courtship song, an intermittent series of buzzes made when other flies are nearby, and (3) the copula song, a brief sound produced by males when they mount a prospective mate. Of these acoustical signals, the calling song may contribute to the attraction process. The calling song was first characterized by Webb et al. (1983b), who described it as low-amplitude vibrations of the wings at a frequency of 200 to $350 \mathrm{~Hz}$ and intensity of 50 to $54 \mathrm{~dB}$ as measured $12 \mathrm{~mm}$ from the male. Recording conducted by Mizrach et al. (2002) confirmed Webb's measurements. 
Until now, almost all research on medfly attractants has focused on chemical lures, or shape and color cues, and there have been few attempts to attract the female fruit flies to the male calling song only. In an early study, Webb et al. (1983a) found that traps for female Caribbean fruit flies baited only with song caught 2.4-fold as many females as silent controls. Recently, Mankin et al. (2000) elaborated on this finding and demonstrated that pre-exposure to male pheromone enhanced the response of female caribflies to male song. However, despite years of research, there is still no commonly used trap to monitor the presence and abundance of mate-seeking female fruit flies.

The objective of the present study is to assess the attraction of mate-seeking female medflies to recordings of male calling song and synthetic sounds as a contribution to the design and testing of a trap (patent pending) based on acoustic lures.

\section{Materials ANd Methods \\ Preparation of Flies}

The sources of the medflies were laboratory mass-reared flies (lab flies) and wild flies. The lab flies were obtained as pupae from the Citrus Marketing Board of Israel from the genetic stock "Vienna," a stock maintained in the laboratory since 1964. Wild flies emerged from parasitized fruits. The pupae were placed in $30 \times 40 \times 20 \mathrm{~cm}$ plastic cages with screened ventilation openings and glass lids, and were kept on a $12 \mathrm{~h}$ L:D light cycle. Males and females were sexed $24 \mathrm{~h}$ after emergence and thereafter were kept in separate cages at temperatures of $24^{\circ} \mathrm{C}$ and on a $12 \mathrm{~h} \mathrm{~L}: \mathrm{D}$ light cycle. The flies were fed water, sugar, and a mixture of sugar and yeast hydrolysate. Virgin females and males were used in bioassays at 3 to 7 days and 14 to 18 days of age for lab and wild flies, respectively.

\section{Source of Recording and Playback of Male Medfly SoundS}

The recordings of male medfly calling songs were made in an anechoic chamber (Mankin et al., 1996) at the USDA-ARS Center for Medical, Agricultural, and Veterinary Entomology and were adapted for the present study. Since the fundamental frequencies of recorded calling songs taken from sterile males were not significantly different from those of wild and laboratory-reared sterile males obtained previously (Sivinski et al., 1989), existing recordings of 3-day old sterile male medflies were used. During the first $4 \mathrm{~h}$ of photophase, the males called frequently in bouts of ca. $350 \mathrm{~Hz}$ wing-fanning vibrations at sound pressure levels ca. $48 \mathrm{~dB}$, similar to those reported by Webb et al. (1983b). Bouts were recorded in an anechoic chamber with a unidirectional microphone (model 4145, B\&K, Naerum, Denmark) positioned about $0.5 \mathrm{~cm}$ above a $10 \times 10 \times 7 \mathrm{~cm}$ screened cage containing three to five males. The microphone, with approximately $\pm 0.5 \mathrm{~dB}$ response in the range $2 \mathrm{~Hz}$ to $10 \mathrm{kHz}$, was connected to a measuring amplifier (model 2610, B\&K). The output was stored on a digital audiotape recorder (model DA-P1, TEAC, Montebello, Cal.) sampled at 44,100 Hz with approximately $\pm 0.5 \mathrm{~dB}$ in the range $20 \mathrm{~Hz}$ to $20 \mathrm{kHz}$.

A representative song chosen for playback in this study was taken from a recorded collection (Mankin et al., 1996). An 8 s segment of calling song recorded from an individual male was selected from the collection for broadcasting in the bioassays. The song segment was played in a continuous loop and amplified with a $100 \mathrm{~W}$ speaker amplifier (Sansui, Japan), which provided up to $110 \mathrm{~dB}$ amplification (100 mm from loudspeaker). A $100 \mathrm{~W}$ sub-midrange 5 in. $(12.7 \mathrm{~cm})$ loudspeaker (Moral, Israel) installed in its original wooden box and equipped with a sound concentration funnel was used as the playback device.

\section{LABORATORY BIOASSAYS}

The behavior of female medflies was observed in bioassays conducted in $60 \times 60 \times 150 \mathrm{~cm}$ Plexiglas and net chambers. Plexiglas chambers provide a clear view, are easier to clean, and are cost-effective. Therefore, it is a common practice to use this type of chamber material to observe insect behavior. All tests with live males were therefore conducted in Plexiglas chambers. Nevertheless, when applying sound pressure, the Plexiglas walls vibrate, so the chamber material was substituted with weave net to avoid bias induced by echo and local vibrations. The experiments were performed in an anechoic room $(400 \times 300 \times 250 \mathrm{~cm})$ with a controlled atmosphere $\left(30^{\circ} \mathrm{C}, 57 \% \mathrm{RH}\right)$. Bioassay chambers were placed lengthwise in the center of the anechoic room. Laboratory tests were performed with three different sound sources: live calling song, played-back calling song, and pure tones.

\section{Live Calling Song Bioassay}

The distribution of female medflies inside a test chamber in response to a live male calling song was examined initially to evaluate the environmental setup without attempting, in this stage, to separate the effects of pheromones from the effects of the sounds. Two techniques were employed: visual counting and capture of landing flies.

The landing behavior of females in response to the presence of live male calling song was examined in a $60 \times$ $60 \times 150 \mathrm{~cm}$ Plexiglas chamber equipped with widely opening doors (fig. 1).

Two cylindrical net cages $(6 \mathrm{~cm}$ long $\times 5 \mathrm{~cm}$ dia.) were placed at mid-height on two opposite sides of the chamber. Sheets of paper $(9 \mathrm{~cm}$ dia., white filter paper, Whatman Laboratory, Brentford, Middlesex, U.K.) were placed next to each net cage as a landing surface (plate) with their planes parallel to the sidewall of the chamber. Five live male medflies were put in one of the net cages, the other cage was left empty as a control, and 40 virgin female lab flies were released in the central part of the chamber. Landings of female flies were observed during the morning and early afternoon periods of peak sexual activity. The number of landings on the plate was recorded every $5 \mathrm{~min}$ for $1 \mathrm{~h}$. The observer remained motionless during the test. The experiment was repeated five times with a fresh group of females each time, yielding 60 counts of landing flies on the paper plate for each side of the chamber. The mean percentage landing of flies next to each net cage, out of the entire female population, was then calculated.

Female flies were captured with a modified electronic fly killer (Titan 30, PestWest Electronics Ltd., Ossett, West Yorkshire, U.K.). The UV bulbs and the zapping screen were removed from the fly killer case, and a helical metal zapper comprising two double helices ( $3 \mathrm{~mm}$ dia wire, $82 \mathrm{~mm}$ helical diameter, $7 \mathrm{~mm}$ helical space, fig. 2) replaced the original screen. 


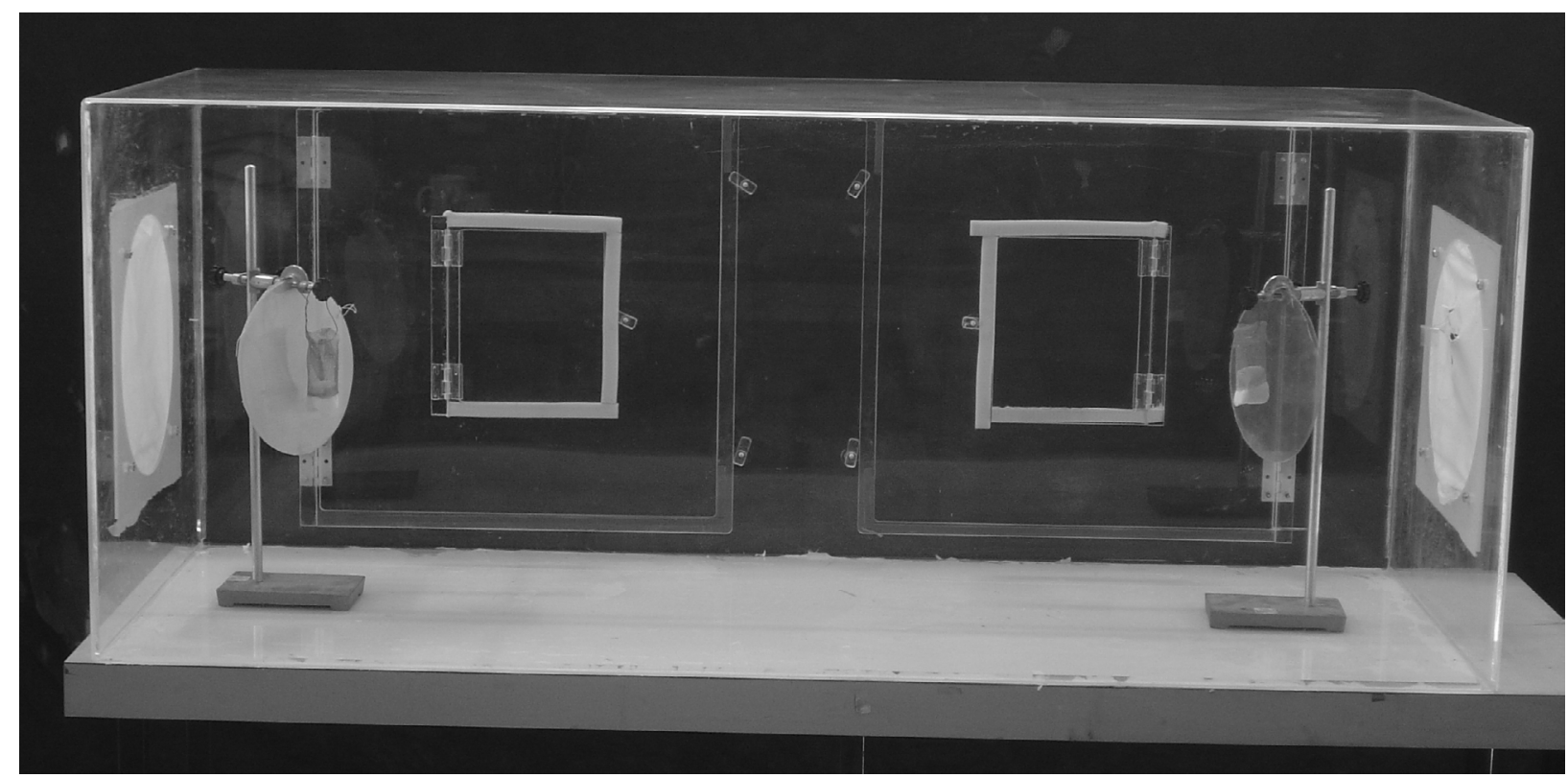

Figure 1. Plexiglas chamber equipped with calling medfly males and control cages and landing plates in both sides of the chamber.

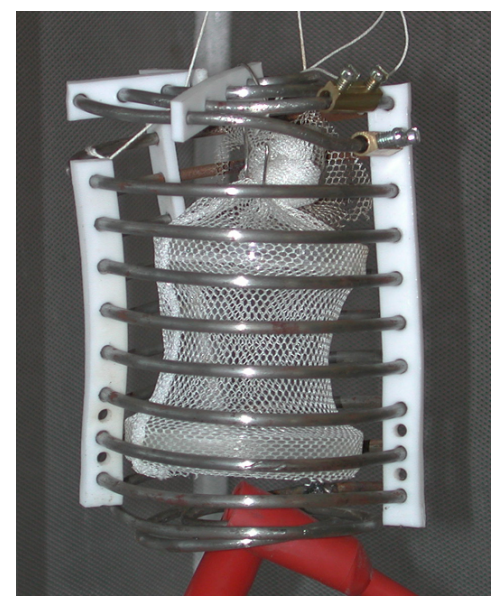

Figure 2. Helical metal zapper screen cages $(50 \mathrm{~mm}$ dia. $\times 80 \mathrm{~mm}$ height).
The two coils that each formed the double helix were fixed and electrically insulated from each other, and each was connected to one outlet of the high-voltage generator of the fly killer. A cylindrical net cage $(6 \mathrm{~cm}$ long $\times 5 \mathrm{~cm}$ dia.) was installed inside each helix and placed at mid-height inside the chamber on opposite sides. To avoid disturbance when flies were first placed into the chamber, a dividing curtain was installed to separate the release section from the zappers. Five live male medflies were put into the cylindrical net cage, and 30 virgin females were released in the center of the chamber. The curtain was lifted 15 min after the flies were introduced. Attracted females that flew toward the calling males had to pass through the zapper wires and were electrocuted within $1 \mathrm{~cm}$ of the screen. The mean percentage of electrocuted flies out of the entire female population was then calculated.

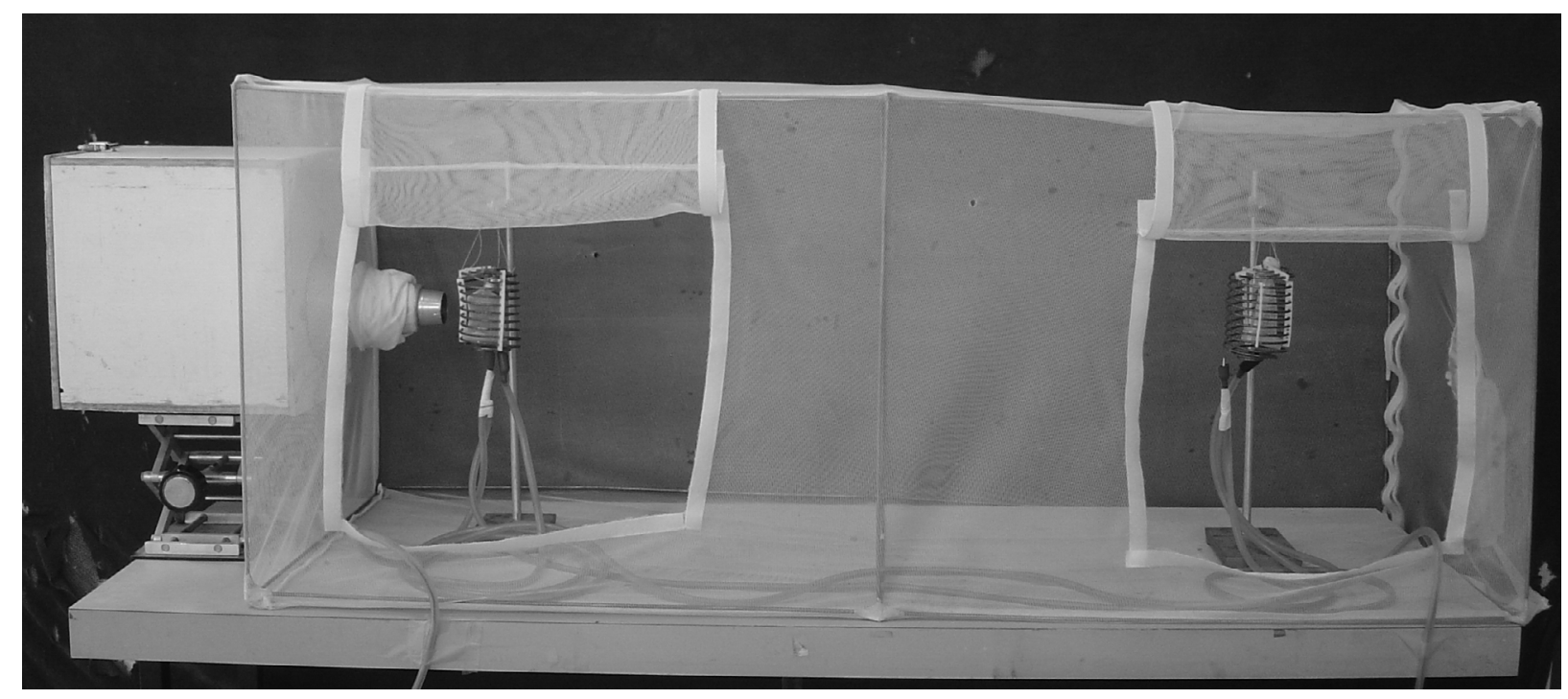

Figure 3. Net chamber equipped with two zapper cages ond one active speaker. 


\section{Calling Song Playback and Pure Tone Attraction Bioassay}

The efficacy of playing recorded male calling song and pure sine-wave tones in attracting wild and lab female flies was evaluated. Since just the female flies were involved at this stage, only the effect of sound was examined. All tests were conducted in a net chamber, $60 \times 60 \times 150 \mathrm{~cm}$ (fig. 3) equipped with two loudspeakers (one active, the other as control) installed one at each end of the cage (long dimension). The length of the chamber $(150 \mathrm{~cm})$ was virtually divided into three equal sections, referred to as "near" (the section closest to the active speaker), "middle," and "far."

Each experiment involved 20 female flies, which were released in the middle of the chamber. Prior to sound playback, the distribution of the flies in the cage was sampled and recorded. The sound was alternated at 10 min intervals at two intensities: 67 and $110 \mathrm{~dB}$ (measured $100 \mathrm{~mm}$ from loudspeaker). It was assumed that the lower intensity, in the range of signals that the female might encounter close to a calling male, would be detectable only over short distances $(<0.5 \mathrm{~m})$. The higher intensity sound was expected to be detectable over distances of $0.5 \mathrm{~m}$ or greater. The "songs" played at the two sound intensities included the male calling song and four pure tones: sine-wave signals at 150, 250, 350, and $450 \mathrm{~Hz}$, based on results of previous experiments by Sivinski et al. (1989) and Webb et al. (1983b).

The visual counting technique was employed during the playback of the song and tones, and the number of flies landing on the chamber walls in each virtual section of the cage was recorded every 10 min for $2 \mathrm{~h}$.

\section{Results AND DisCussions}

\section{Live Calling Song Bioassay}

The mean percentage landing of female medflies on the paper plate next to the male net in response to the live male calling song was $72.8 \pm 13.9 \%$ of the population $(\alpha=0.05)$. No flies landed on the control paper plate during the same period. This relatively high landing percentage was expected and confirms similar results reported in the literature. Therefore, we assumed that flies' behavior is not affected by the experimental setup. Pheromones emitted by medfly males are obviously part of the courtship phenomenon and probably contributed to the female response.

The mean percentage electrocution of female medflies by the zapper next to the male cage was $47.4 \pm 7.9 \%(\alpha=0.05)$, and that by the control zapper (no males) was $9.1 \pm 4.5 \%(\alpha=$ $0.05)$. The results indicated the expected significant preferences of the female medfly for the side of the chamber where the male flies were placed.

Although similar numbers of medflies were used in the paper plate treatments and in the zapper treatments, the number of live females landing next to the male cage was higher than the number of females exterminated by the zapper at the same location. At the other end, next to the control (empty) cage, no female flies were observed, while some were eliminated by the zapper. The difference may be due to the nature of the zapper, which kills any straying fly in its vicinity, while random observations missed those flies.

\section{Calling Song Playback and Pure Tone Attraction BiOASSAY}

A control bioassay examined the distribution of female lab flies and wild flies in the net chamber when no sound was played. The visual technique was employed to count the number of flies in each of the three virtually divided sections (near, middle, far) in the net chamber.

We expected that the distribution of flies in the control chamber would be uniform, and, in fact, the mean values in the control count of the lab flies followed such a pattern. However, the landings of wild flies showed a non-uniform spatial distribution in the control chamber; they showed a significant preference for the middle section of the chamber (table 1).

We are not able to explain this bias; therefore, we have used this spatial distribution as our reference (baseline), and observations were normalized accordingly.

The normalization used the following approximation model:

$$
\bar{A}_{i} \cong \frac{\bar{a}_{i}}{n \bar{c}_{i}}, i \in[1 \ldots n]
$$

where $\bar{A}_{i}$ is the adjusted count of flies attracted or electrocuted, $\bar{a}_{i}$ is the observed count of flies, $\bar{c}_{i}$ is the average of the observed counts of flies in the control treatment, and $n$ is the number of sections in the chamber $(n=3)$. The variance of the adjusted counts was estimated by means of the first-order Taylor approximation (Cochran, 1977):

$$
S^{2}=\sum_{i} S_{i}^{2}\left(\frac{\partial f}{\partial x_{i}}\right)^{2}
$$

where $S^{2}$ is the estimated variance of the adjusted count of flies $\left(\bar{A}_{i}\right), S_{i}{ }^{2}$ are the observed variances of the counts of flies when sound were presented $\left(S_{a}{ }^{2}\right)$ and in the control $\left(S_{c}{ }^{2}\right), f$ $(a, c)$ is the adjustment model (eq. 1), and $x_{i}$ are the observed counts in the playback $(a)$ and control $(c)$ treatments.

Adjusted percentages of landing results of female lab flies attracted by male calling song playback and by continuous sine tones at low and high intensities of 67 and $110 \mathrm{~dB}$ are summarized in figures 4 and 5, respectively. When sounds were played at an intensity of $67 \mathrm{~dB}$ (fig. 4), the female flies preferred to land near the speaker in response to all tones, except for the "calling song," which elicited no significant preference. When the same sounds were played at an intensity of $110 \mathrm{~dB}$ (fig. 5), no significant preferences were observed in response to the pure tones, but when the "calling song" was played, the female lab flies significant preferred to land by the "near" speaker.

Table 1. Number of flies located in each of the three virtually divided sections (near, middle, far) in the net chamber. The control

\begin{tabular}{|c|c|c|c|c|c|c|}
\hline & \multicolumn{2}{|c|}{$\begin{array}{c}\text { Near the } \\
\text { Loudspeaker }\end{array}$} & \multicolumn{2}{|c|}{$\begin{array}{l}\text { Middle Part } \\
\text { of the Cage }\end{array}$} & \multicolumn{2}{|c|}{$\begin{array}{c}\text { Far End } \\
\text { of the Cage }\end{array}$} \\
\hline & Mean[a] & STD & $\operatorname{Mean}^{[a]}$ & STD & $\operatorname{Mean}^{[a]}$ & STD \\
\hline Lab flies & $7.00 \mathrm{a}$ & 1.41 & $6.25 \mathrm{a}$ & 1.50 & $6.75 \mathrm{a}$ & 0.96 \\
\hline Wild flies & $3.86 \mathrm{c}$ & 2.04 & $9.29 \mathrm{a}$ & 2.56 & $6.86 \mathrm{~b}$ & 1.46 \\
\hline
\end{tabular}
treatment included no external audio intervention.

[a] Means in the same row followed by the same letter are not significantly different by Duncan's multiple range test ( $\mathrm{p}<0.05)$. (SAS, 1992). 


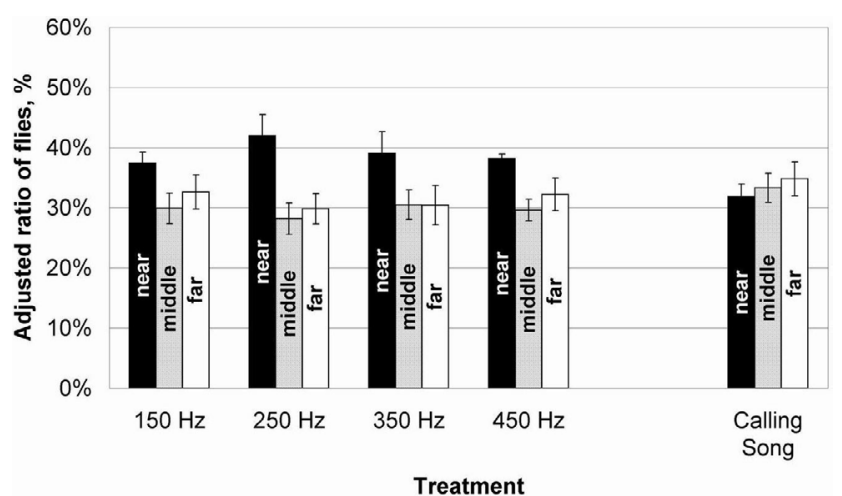

Figure 4. Adjusted percentages of female lab flies attracted by continuous sine tones and by male calling song playback at $67 \mathrm{~dB}$ sound intensity; vertical lines delineate confidence limits of the mean value $(\alpha=0.05)$.

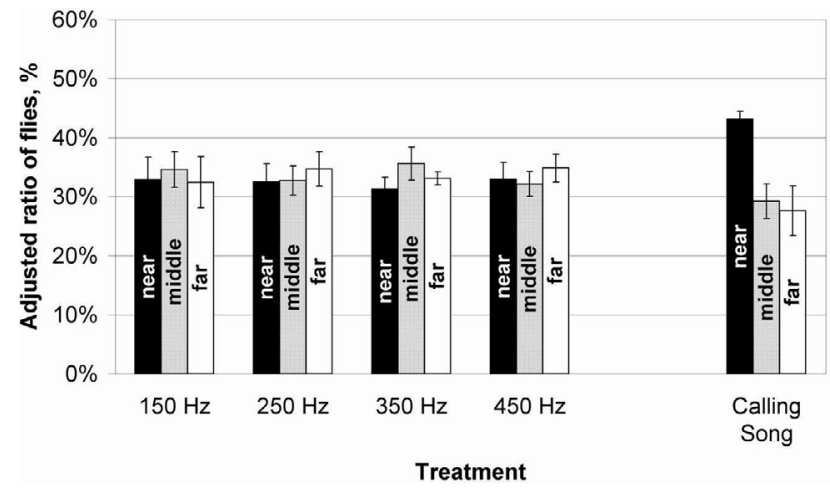

Figure 5. Adjusted percentages of female lab flies attracted by continuous sine tones and by male calling song playback at $110 \mathrm{~dB}$ sound intensity; vertical lines delineate confidence limits of the mean value $(\alpha=0.05)$.

Adjusted percentages of wild female flies attracted by male calling song playback and by continuous sine tones at low and high intensities of 67 and $110 \mathrm{~dB}$ are summarized in figures 6 and 7, respectively. In almost all treatments, the wild female flies significantly preferred to land "near" the speaker, with the exception of the "calling song" played at $67 \mathrm{~dB}$, which elicited only marginal preference for the "near" landing site. Increased sound intensity (from 67 to $110 \mathrm{~dB}$ ) reduced the attractiveness of the speaker for all females, both lab and wild, possibly because the flies were repelled by the presence of intense sound that they did not normally encounter.

Overall, as depicted in figures 4 to 7 , lower intensities $(67 \mathrm{~dB})$ were relatively more attractive to the females than higher intensities $(110 \mathrm{~dB})$. Nevertheless, the calling song depicted inverted behavior: higher intensity attracted more flies (both lab and wild flies) with respect to the sine tones. Wild flies were attracted to the synthetic tones more than lab flies. A lower frequency $(150 \mathrm{~Hz})$ attracted more flies than higher frequencies ( 250 to $450 \mathrm{~Hz}$ ) when the calling song was played at $67 \mathrm{~dB}$ sound intensity. The behavioral explanation for these phenomena is beyond the scope of this work and calls for further study. In addition, this was only a feasibility study conducted in the laboratory, and the relative effectiveness of the different sounds should be tested in field studies.

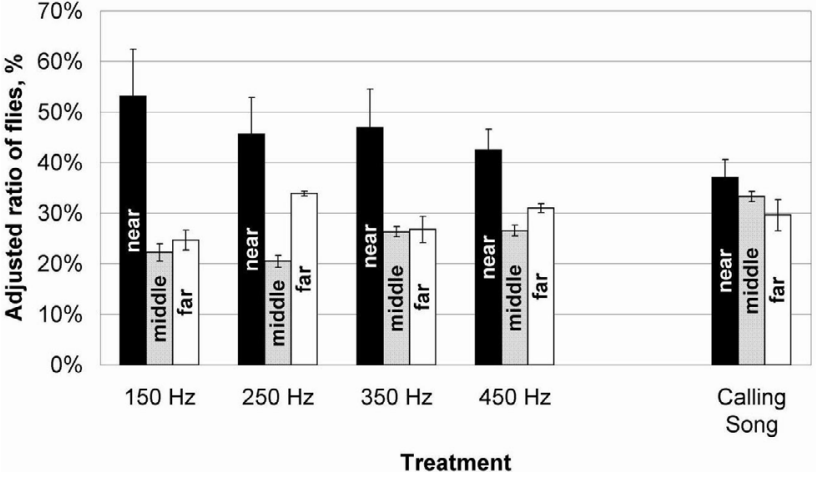

Figure 6. Adjusted percentages of female wild flies attracted by continuous sine tones and by male calling song playback at $67 \mathrm{~dB}$ sound intensity; vertical lines delineate confidence limits of the mean value $(\alpha=0.05)$.

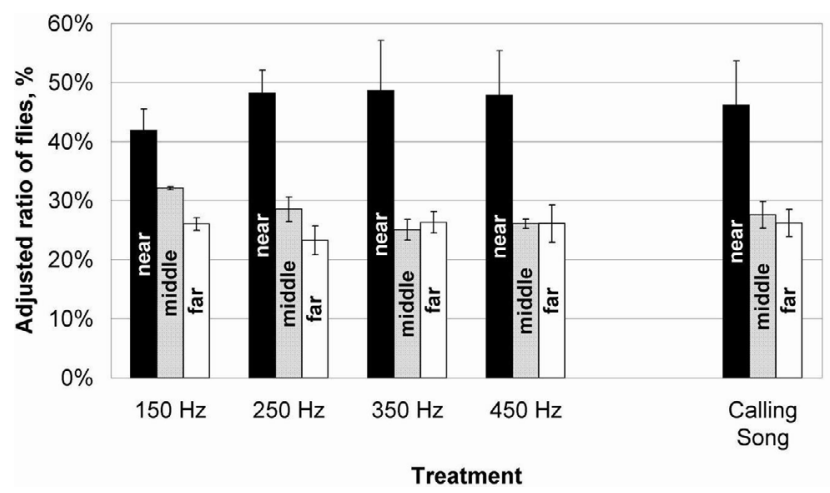

Figure 7. Adjusted percentages of female wild flies attracted by continuous sine tones and by male calling song playback at $110 \mathrm{~dB}$ sound intensity; vertical lines delineate confidence limits of the mean value $(\alpha=0.05)$.

\section{Conclusion}

To consider the feasibility of developing a female-targeted acoustic trap for medflies, we first observed females in the presence and absence of a broadcast calling song to identify responses that showed potential to increase trap captures. The findings of the bioassay test of the attraction of females to the presence of male flies agreed with the known and expected behavior. Thus, it can be concluded that the experimental setup employed in this study had no influence on the expected behavior of flies.

In most bioassay experiments where sounds were played to lab flies and to wild flies, the female flies were attracted to sites near speakers in preference to sites without sound. Synthetic sounds emitted at $67 \mathrm{~dB}$ yielded the best results in attracting female flies. It can be concluded that the technique employed here can be used to attract female flies in order to monitor and control the fruit fly pest. However, further optimization of sound intensity might improve female attraction and needs further research.

These results demonstrate that synthetic tones that mimic male song may be used to lure female medflies into traps. Further, they suggest that synthetic tones can be more effective than recordings of actual male song. In addition, the experiments described herein suggest that the responses of laboratory-reared strains of insects are not identical to the responses of their wild counterparts. 


\section{ACKNOWLEDGEMENTS}

This research was supported in part by Grant No. IS-3137-99 from BARD, the United States-Israel Binational Agricultural Research and Development Fund. Contribution from the Institute of Agricultural Engineering, the Agricultural Research Organization, the Volcani Center, Bet Dagan, Israel, No. 709/03, 2003 series.

\section{REFERENCES}

Cochran, W. G. 1977. Sampling Techniques. London, U.K.: John Wiley and Sons.

Fimiani, P. 1989. Mediterranean region. In Fruit Flies: Their Biology, Natural Enemies, and Control, 39-50. A. S. Robinson and G. H. S. Hooper, eds. Amsterdam, The Netherlands: Elsevier.

Heath, R. R., P. J. Landolt, J. H. Tumlinson, D. L. Chambers, R. E. Murphy, R. E. Doolittle, B. D. Dueben, J. Sivinski, and C. O. Calkins. 1991. Analysis, synthesis, formulation, and field testing of three major components of male Mediterranean fruit fly pheromone. J. Chem. Ecol. 17(9): 1925-1940.

Jang, E. B., and D. M. Light. 1996. Olfactory semiochemicals of Tephritids. In Fruit Fly Pests: A World Assessment of Their Biology and Management, 73-90. B. A. McPheron and G. J. Steck, eds. Delray Beach, Fla.: St. Lucie Press.

Mankin, R. W., A. Malavasi, and C. Aquino. 1996. Acoustical comparisons of calling songs from Anastrepha species in Brazil. In Fruit Fly Pests: A World Assessment of Their Biology and Management, 37-42. B. A. McPheron and G. J. Steck, eds. Delray Beach, Fla.: St. Lucie Press.
Mankin, R. W., W. E. Petersson, N. D. Epsky, R. R. Heath, and J. Sivinski. 2000. Exposure to male pheromones enhances Anastrepha suspensa (Diptera: Tephritidae) female response to male calling song. Florida Entomol. 83(4): 411-421.

Mazor, M., S. Gothilf, and R. Galun. 1987. The role of ammonia in the attraction of females of the Mediterranean fruit fly to protein hydrolysate baits. Entomol. Exp. Appl. 43(1): 25-29.

Mizrach, A., R. W. Mankin, M. Mazor, A. Hetzroni, D. Shuman, N. Epsky, R. R. Heath, and J. Grinshpun. 2002. Male song as a tool for trapping female medflies. Grant No. IS-3137-99 Final Report. Binational (U.S. - Israel) Agricultural Research and Development Funds (BARD). Available at: www.bard-isus.com/frabst/3137.htm.

Rossler, Y. 1989. Insecticidal baits and cover sprays. In Fruit Flies: Their Biology, Natural Enemies, and Control, 329-336. A. S. Robinson and G. H. S. Hooper, eds. Amsterdam, The Netherlands: Elsevier Science.

Rossler, Y., and C. Chen. 1994. The Mediterranean fruit fly, Ceratitis capitata, a major pest of citrus in Israel, its regulation and control. EPPO Bulletin 24(4): 813-816.

SAS. 1992. Users Guide: Statistics, 6.08 ed. Cary, N.C.: SAS Institute, Inc.

Sivinski, J., C. O. Calkins, and J. C. Webb. 1989. Comparisons of acoustic courtship signals in wild and laboratory reared Mediterranean fruit fly Ceratitis capitata. Florida Entomol. 72(1): 212-214.

Webb, J. C., T. Burk, and J. Sivinski. 1983a. Attraction of female Caribbean fruit flies, Anastrepha suspensa (Diptera: Tephritidae), to the presence of males and male-produced stimuli in field cages. Ann. Entomol. Soc. of America 76(6): 996-998.

Webb, J. C., C. O. Calkins, D. L. Chambers, W. Schwienbacher, and K. Russ. 1983b. Acoustical aspects of behavior of Mediterranean fruit fly, Ceratitis capitata: Analysis and identification of courtship sounds. Entomol. Exp. Appl. 33(1): 1-8. 